\title{
PtFeCu Concave Octahedron Nanocrystals as Electrocatalysts for Methanol Oxidation Reaction
}

Yuanyuan Zhang, Rui Shi, Jing Ren, Yang Dai, Yijie Yuan, Zhenghua Wang*

Key Laboratory of Functional Molecular Solids, Ministry of Education, College of Chemistry and Materials Science, Anhui Normal University, Wuhu 241000, P. R. China

*Corresponding author. E-mail: zhwang@ahnu.edu.cn 


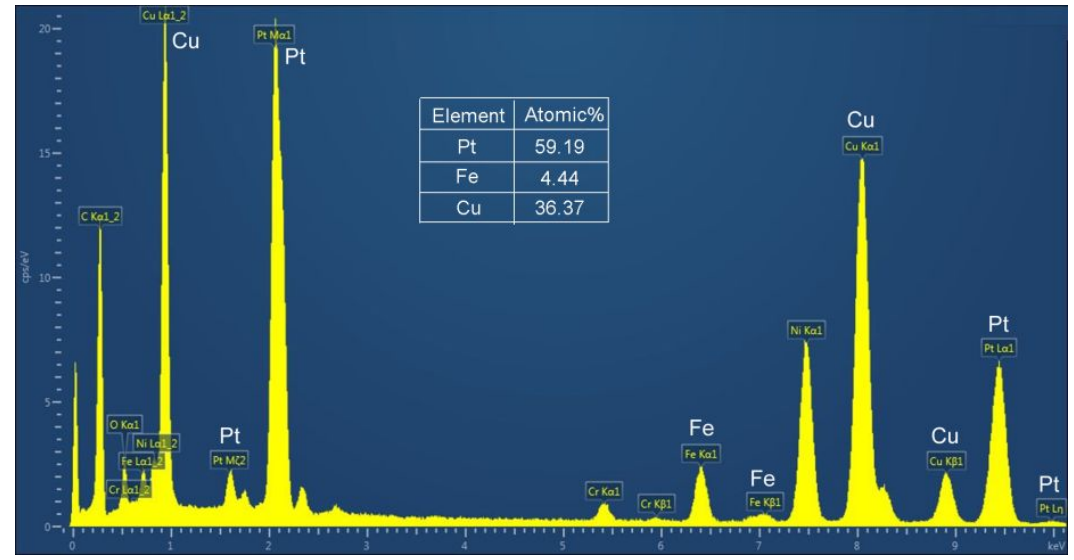

Figure S1 EDS spectrum of the $\mathrm{PtFeCu}$ concave octahedron nanocrystals, the peaks of $\mathrm{Ni}, \mathrm{Cr}$ and $\mathrm{C}$ come from the TEM grid.

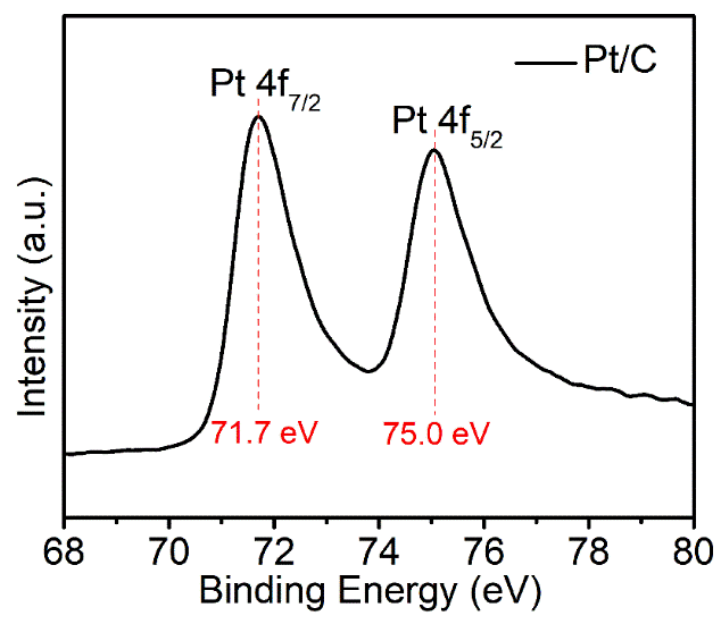

Figure S2 Pt 4f XPS spectrum of Pt/C.

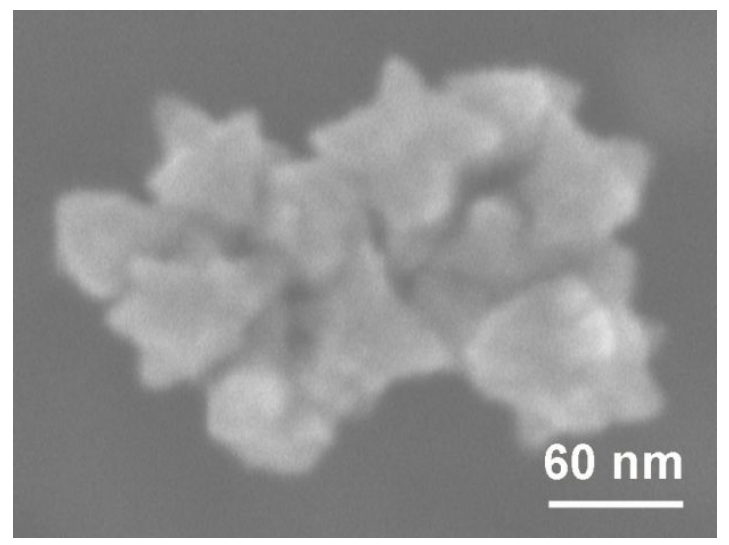

Figure S3 SEM image of the $\mathrm{PtFeCu}$ concave octahedron nanocrystals. 

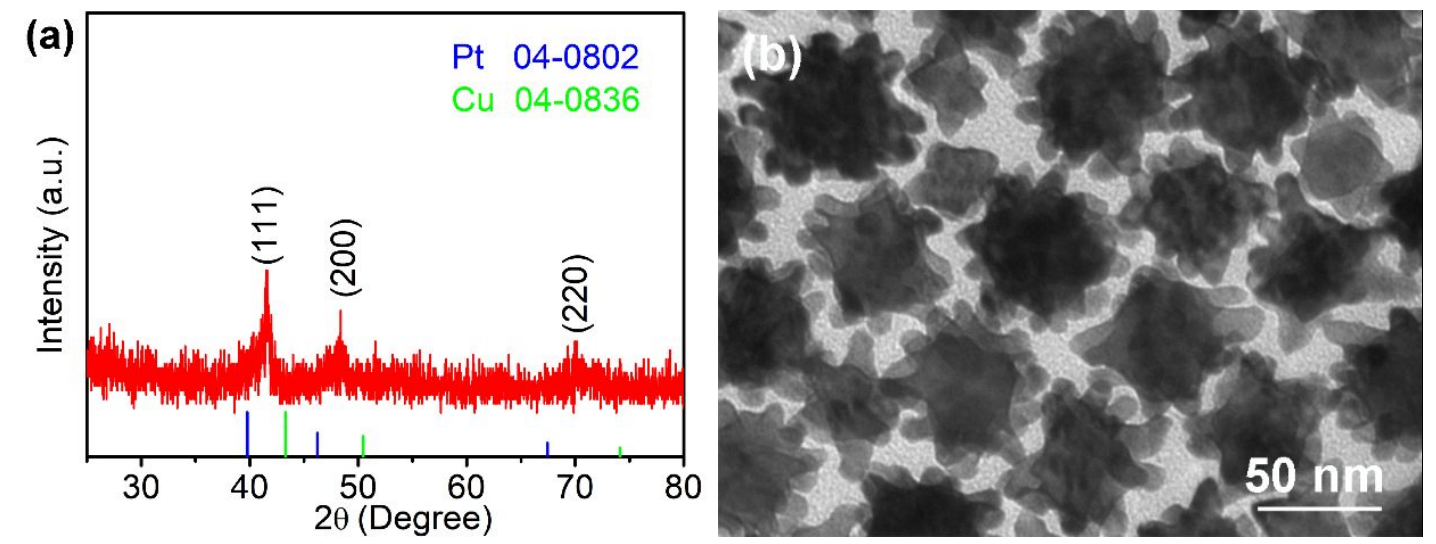

Figure S4 (a) XRD pattern and (b) TEM image of the PtCu nanocrystals.
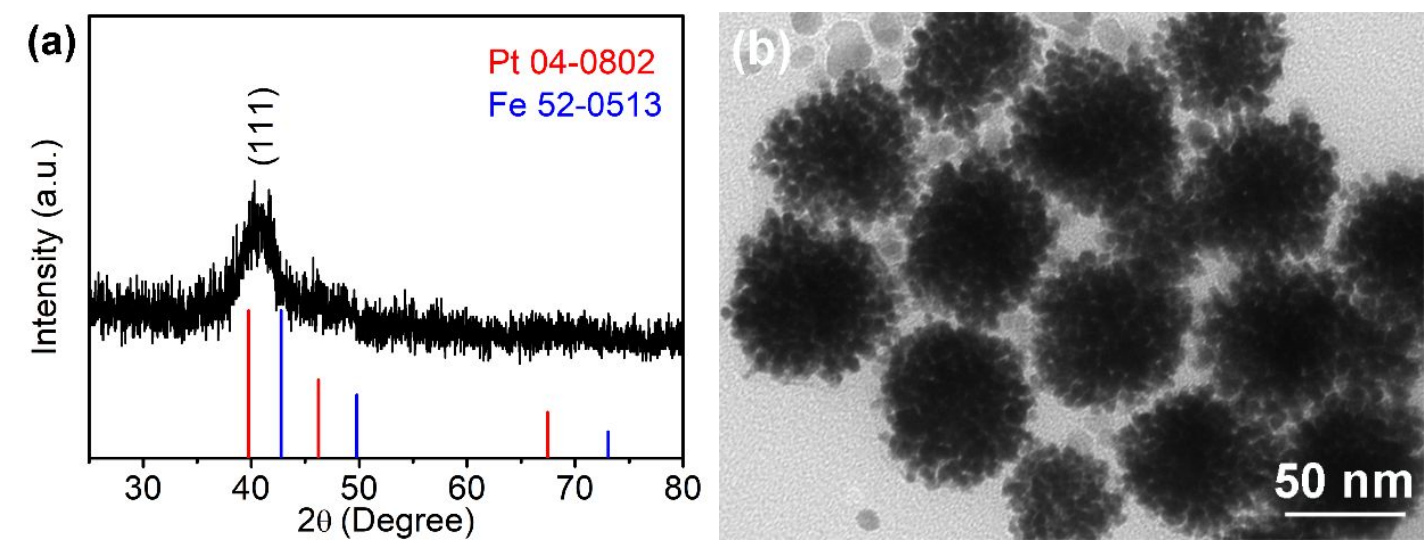

Figure S5 (a) XRD pattern and (b) TEM image of the PtFe nanocrystals.
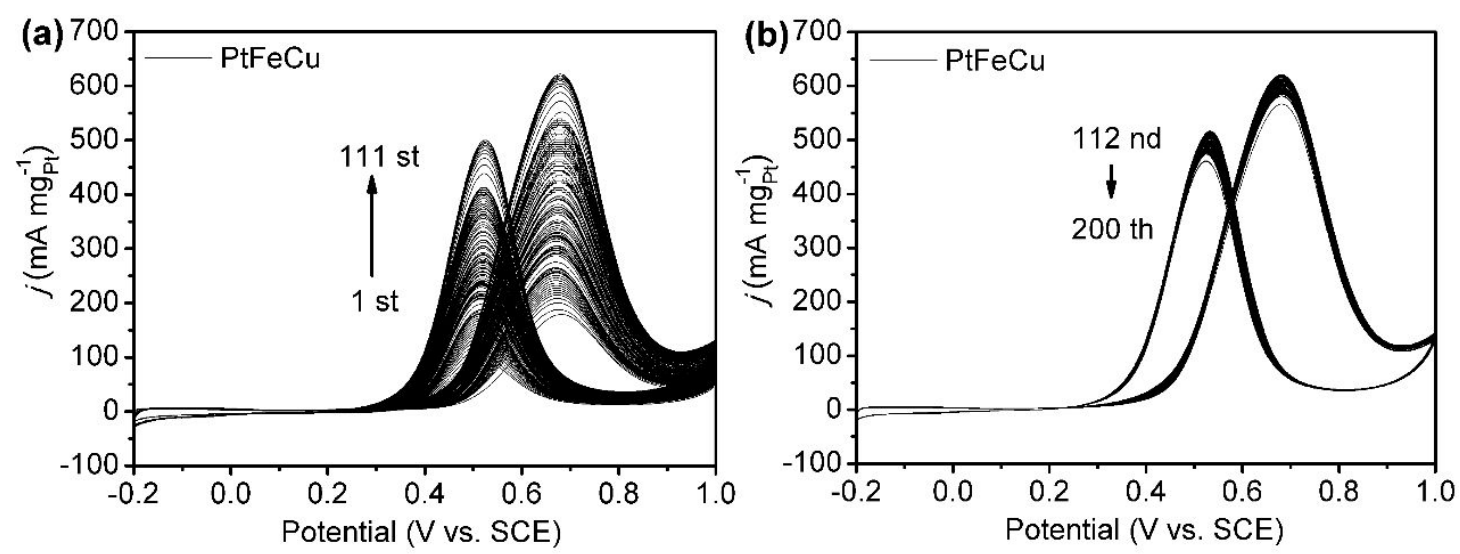

Figure S6 CVs of PtPdCu nanodendrites from the $1^{\text {st }}$ to the 111 st cycles (a) and from the $112^{\text {nd }}$ to the $200^{\text {th }}$ cycles (b). The scan rate of all the CVs is $50 \mathrm{mV} \mathrm{s}^{-1}$. 

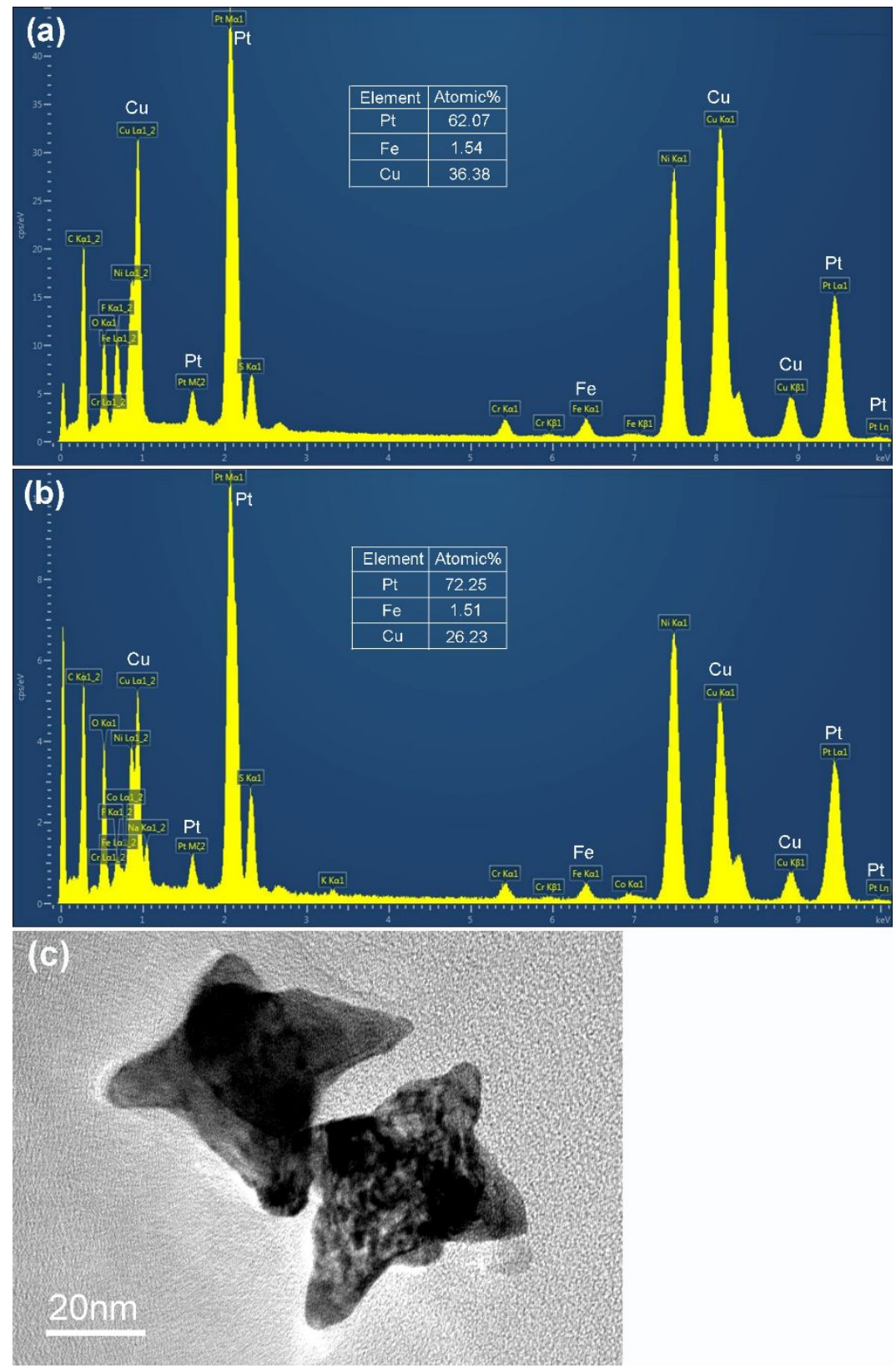

Figure S7 EDS spectrum of the $\mathrm{PtFeCu}$ concave octahedron nanocrystals after $\mathrm{CV}$ test for 111 cycles (a) and 200 cycles (b), the peaks of $\mathrm{Ni}, \mathrm{Cr}$ and $\mathrm{C}$ come from the TEM grid; (c) TEM image of the PtFeCu sample after the 200 cycles $\mathrm{CV}$ test. 